\title{
Perspective
}

PERSPECTIVE Actualité en histoire de l'art

Comptes rendus | 2009

\section{Eva Hanke, Malerbildhauer der italienischen \\ Renaissance von Brunelleschi bis Michelangelo, Petersberg, Michael Imhof Verlag, 2009}

\section{Raphaël Rosenberg}

\section{(2) OpenEdition}

Édition électronique

URL : http://journals.openedition.org/perspective/2569

DOI : 10.4000/perspective.2569

ISSN : 2269-7721

Éditeur

Institut national d'histoire de l'art

Référence électronique

Raphaël Rosenberg, «Eva Hanke, Malerbildhauer der italienischen Renaissance von Brunelleschi bis

Michelangelo, Petersberg, Michael Imhof Verlag, $2009 »$, Perspective [En ligne], Comptes rendus, mis en ligne le 04 septembre 2013, consulté le 01 octobre 2020. URL : http://journals.openedition.org/ perspective/2569; DOI : https://doi.org/10.4000/perspective.2569 
Eva Hanke, Malerbildhauer der italienischen Renaissance von Brunelleschi bis Michelangelo, Petersberg, Michael Imhof Verlag, 2009

Raphaël Rosenberg

\section{RÉFÉRENCE}

Eva Hanke, Malerbildhauer der italienischen Renaissance von Brunelleschi bis Michelangelo, Petersberg, Michael Imhof Verlag, 2009. 
1 Le phénomène des artistes actifs dans plusieurs arts est très courant, surtout à la période moderne, mais n'avait pas encore fait l'objet d'une étude approfondie. Eva Hanke établit un catalogue exhaustif de 105 peintres-sculpteurs de la Renaissance italienne - de Brunelleschi et Pisanello à Michel-Ange et Beccafumi, des Abruzzes et de l'Ombrie jusqu'à Gênes et au Frioul, en tenant compte de tous ceux qui, audelà de la peinture, furent aussi orfèvres, médailleurs, sculpteurs de bois, de pierre ou de bronze. Le livre combine l'analyse de la théorie des arts et une recherche sociologique de l'éducation des artistes, du marché et des corporations avec l'étude approfondie d'œuvres peintes et sculptées par le même artiste. Il en ressort

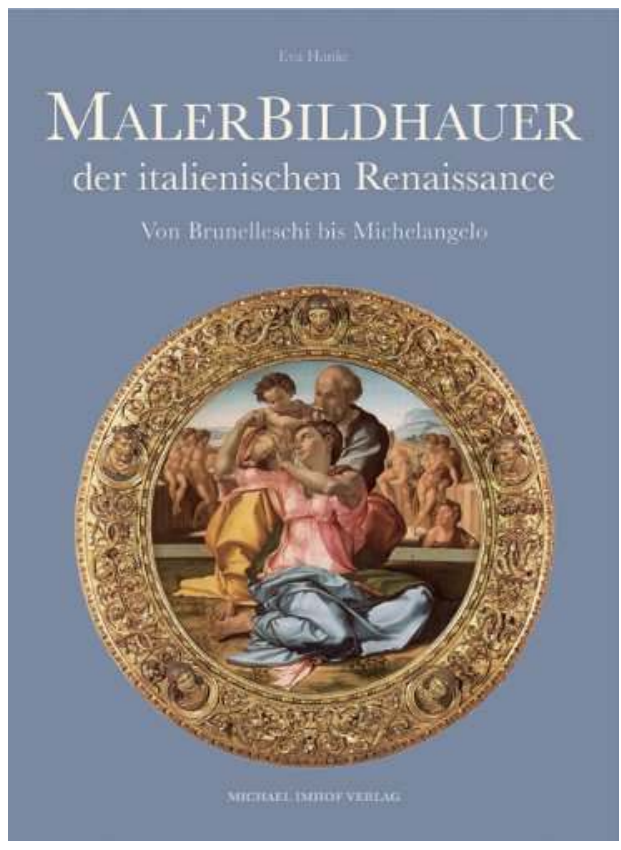
que l'avantage d'une double profession était tout d'abord d'ordre économique, permettant de mieux s'adapter à la demande. Avec la croissance du prestige social de l'artiste, la polyvalence devint un critère d'estime. Les pages les plus marquantes du livre sont celles dédiées à l'analyse des formes et du style des peintres-sculpteurs. L'auteur montre dans de nombreux exemples comment la sculpture a influencé la peinture et réciproquement. Elle établit une nouvelle base pour la comparaison des deux media et développe une série de catégories novatrices qui pourront servir à la comparaison des deux arts bien au-delà de la Renaissance italienne. 